\section{Racial disparity in arthroplasty remains disjointed}

I read with interest the article entitled 'Racial disparities in knee and hip total joint arthroplasty: an 18-year analysis of national medicare data' by Singh et al. ${ }^{1}$ I congratulate the authors for successfully contributing to the increasing literature of racial disparity in total joint arthroplasty (TJA) research by analysing trends over an 18-year period and including both usage and outcomes. The persistently reduced standardised utilisation rates among black patients for both primary and revision total knee (TKA) and total hip arthroplasty (THA) procedures throughout the entire duration of the study are concerning; however, it is even more alarming that a magnitude increase in disparity occurred for primary TKA usage from 1991 to 2008.

A limitation acknowledged by the authors in using US Medicare Provider Analysis and Review (MedPAR) data is the prevention to evaluate use disparities among racial groups in patients aged $<65$ years. Interestingly, although Chen $e t a l^{2}$ also noted a lower total probability of THA and TKA among black patients compared with white patients using the National Inpatient Sample data from 2002 to 2007, there was a higher probability of black patients having THA and TKA compared with white patients among the age groups of 45-54 years and 55-64 years, whereas the reverse was seen in the age groups of 65-74 years and 75-84 years. Understanding this age-related variance may provide insight into addressing racial disparities in the $>65$-year-old cohort.

Although identification of disparities in receipt of revision arthroplasty between racial groups is known, defining the key level (system, provider or patient) at which to counteract such disparity is more elusive. Hausmann et $a l^{3}$ showed that the rates of recommendation for TJA were less in black patients compared with whites among Veteran Affairs orthopaedic clinics but this difference was not significant after adjusting for surveyed patient preference for TJA. After adjusting for additional factors, several studies corroborate patient preference and willingness to undergo a procedure as a major influence in receipt of arthroplasty. ${ }^{4-7}$ The Department of Health and Human Services (HHS) recently outlined an action plan to reduce racial and ethnic disparities. ${ }^{8}$ However, this was largely focused on healthcare coverage and access as well as HHS efficiency and transparency. While system level changes are being evaluated, more focused and coordinated efforts are needed at the provider and patient level. Persistent disparity within a Medicare population, as shown by Singh et al, ${ }^{1}$ provides further evidence that healthcare coverage is not the leading barrier to arthroplasty. Patients, themselves, are key stakeholders and we must engage and employ them to be involved in the process of identifying areas that providers can address and correct to bridge the disparity gap. Understanding how to appropriately recognise ethnic variation in preferences and perception of benefit are skills that providers must learn to combat this growing inequality. Funding for research and education in this area is requisite from orthopaedic, rheumatology and primary care professional organisations.

\section{Matthew J Koster}

Correspondence to Dr Matthew J Koster, Department of Internal Medicine, Division of Rheumatology, Mayo Clinic, Rochester, MN, USA;

koster.matthew@mayo.edu

\section{Competing interests None.}

Provenance and peer review Not commissioned; internally peer reviewed.

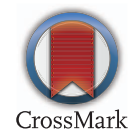

To cite Koster MJ. Ann Rheum Dis 2015;74:e23.

Received 10 November 2014

Accepted 15 November 2014

Published Online First 4 December 2014

Ann Rheum Dis 2015;74:e23. doi:10.1136/annrheumdis-2014-206963

\section{REFERENCES}

1 Singh JA, Lu X, Rosenthal GE, et al. Racial disparities in knee and hip total joint arthroplasty: an 18-year analysis of national medicare data. Ann Rheum Dis 2014;73:2107-15.

2 Chen J, Rizzo JA, Parasuraman S, et al. Racial disparities in receiving total hip/knee replacement surgery: the effect of hospital admission sources. J Health Care Poor Underserved 2013;24:135-51.

3 Hausmann LR, Mor M, Hanusa BH, et al. The effect of patient race on total joint replacement recommendations and utilization in the orthopedic setting. J Gen Intern Med 2010;25:982-8.

4 Ibrahim SA, Siminoff LA, Burant CJ, et al. Understanding ethnic differences in the utilization of joint replacement for osteoarthritis: the role of patient-level factors. Med Care 2002:40:144-51

5 Kroll TL, Richardson M, Sharf BF, et al. "Keep on truckin" or "It's got you in this little vacuum": race-based perceptions in decision-making for total knee arthroplasty. J Rheumatol 2007:34:1069-75.

6 Suarez-Almazor ME, Souchek J, Kelly PA, et al. Ethnic variation in knee replacement: patient preferences or uninformed disparity? Arch Intern Med 2005;165:1117-24.

7 Figaro MK, Russo PW, Allegrante JP. Preferences for arthritis care among urban African Americans: "I don't want to be cut". Health Psychol 2004;23:324-9.

8 Koh HK, Graham G, Glied SA. Reducing racial and ethnic disparities: the action plan from the department of health and human services. Health Aff (Millwood) 2011:30:1822-9. 